\title{
BMJ Global Health Using scientific authorship criteria as a tool for equitable inclusion in global health research
}

\author{
Nadia Adjoa Sam-Agudu (D) , 1,2,3 Seye Abimbola (D) ${ }^{4,5}$
}

To cite: Sam-Agudu NA, Abimbola S. Using scientific authorship criteria as a tool for equitable inclusion in global health research. BMJ Global Health 2021;6:e007632. doi:10.1136/ bmjgh-2021-007632

Received 5 0ctober 2021 Accepted 5 October 2021

D) Check for updates

(C) Author(s) (or their employer(s)) 2021. Re-use permitted under CC BY-NC. No commercial re-use. See rights and permissions. Published by BMJ.

${ }^{1}$ International Research Center of Excellence, Institute of Human Virology Nigeria, Abuja, Nigeria

2Department of Paediatrics and Child Health, University of Cape Coast School of Medical Sciences, Cape Coast, Ghana ${ }^{3}$ Institute of Human Virology, University of Maryland School of Medicine, Baltimore, Maryland, USA

${ }^{4}$ School of Public Health, University of Sydney, Sydney, New South Wales, Australia ${ }^{5} J u l i u s$ Global Health, University Medical Center, Utrecht University, Utrecht, The Netherlands

Correspondence to Dr Seye Abimbola;

Seye.Abimbola@sydney.edu.au

\section{INTRODUCTION}

In 1985, the International Committee of Medical Journal Editors (ICMJE) created a standardised set of criteria for authorship. ${ }^{1}$ The central principle underlying these criteria is that authorship is an intellectual activity that entails contributions to ideas (eg, conceptualising a study and framing the research question), analyses (eg, formulating the analysis approach/framework and/or performing the actual analysis), writing (and revising the manuscript) and ownership (of the study or research project). The ICMJE criteria have been broadly adopted by biomedical and health journals, including those focused on global health research. They have also been revised over time to accommodate emerging issues and concerns: for example, recognising author roles such as data acquisition (2000 revision $)^{2}$ and the need for all authors to be accountable for the work (2013 revision). ${ }^{3}$

The ICMJE recommends that authorship be based on meeting all the following four criteria $^{4}$ :

1. 'Substantial contributions to the conception or design of the work; or the acquisition, analysis, or interpretation of data for the work; AND

2. Drafting the work or revising it critically for important intellectual content; AND

3. Final approval of the version to be published; AND

4. Agreement to be accountable for all aspects of the work in ensuring that questions related to the accuracy or integrity of any part of the work are appropriately investigated and resolved'.

While these guidelines are widely accepted, compliance is limited and interpretations vary. ${ }^{5-8}$ They are also open to being used to exclude or to obscure the contribution of some authors, ${ }^{8-10}$ rather than an opportunity for inclusion and transparency. In this editorial, we highlight how the ICMJE criteria can be used proactively for author inclusion and not exclusion, in line with the recently published 'Consensus statement on measures to promote equitable authorship of research publications from international partnerships. ${ }^{11}$ We highlight the context of applying the ICMJE criteria in research partnerships between high-income country (HIC) and low-income and middle-income country (LMIC) teams. The power imbalances in such collaborations are well documented, in that HIC participants typically have more decision-making power based largely on their institutional resources and acquisition of funding. ${ }^{1-13}$ In this context, leaders of such research collaborations should pay particular attention to the 'or's in ICMJE criteria 1 and 2.

\section{CRITERION 1}

Substantial contributions to the conception or design of the work; or the acquisition, analysis or interpretation of data for the work.

The first criterion is explicit about the broad range of contributions that qualify an individual as an author. While ICMJE does not define what constitutes substantial contribution under criterion 1 , in the context of authorship, 'substantial' has been interpreted to mean 'contribution without which a part of the work or even the entire work could not have been completed ${ }^{14}$ It is a condition that local team members will readily satisfy, given the range of options for contribution under criterion 1 . If the study was partially or fully conceptualised and designed in the study setting (as ought to be the case), and/ or people in those settings were involved in data acquisition (as is most certainly the case) and/or analysing and interpreting the data, then it is highly likely that most people who fulfil this criterion are local. Indeed, this is not a criterion that is typically used to disqualify potential local authors. 
Where LMIC authors often lack robust contributioneither by intention or circumstance-is data analysis. For example, LMICs score significantly lower than HICs in the World Bank's statistical capacity indicators. ${ }^{15}$ Local team members may not be invited to participate, based on conscious biases or assumptions (justified or not) that they lack the requisite skills. Even where capacity is truly limited, this should be seen as an opportunity for capacity-building by both LMIC and HIC experts on the team. This facilitates authorship inclusion-by ensuring that local team members are actively involved in data analysis, contributing as they enhance their skills. However, in addressing capacity-building needs in HIC-LMIC collaborations, one should be careful not to assume that capacity deficit lies exclusively among LMIC team members, or that HIC team members exclusively possess the requisite skills.

Data interpretation in international research partnerships ought to be a collective exercise in which local team members are considered to have privileged knowledge, given their greater contextual exposure and expertise regarding the topic under study. ${ }^{16}$ This knowledge can be applied during data analysis and is also relevant to the framing of the research question, which determines what data to acquire and analyses to conduct. Hence, interpretation is integral to all the other elements of criterion 1 -that is, conception, design, data acquisition and data analysis. Where local team members lack the skills to fully interpret the data, this too should be seen as an opportunity for capacity-building.

As the new 'normal' in the COVID-19 era demonstrates, these tasks (data analysis, interpretation and capacitybuilding for both) can be conducted virtually. Aspects of data analysis and interpretation can be completed and documented via email or recorded virtual team meetings such as conference calls. Relevant input during these virtual meetings can then be considered ICMJE criteriafulfilling author contributions from local (and non-local) team members. Team leadership can proactively structure meeting agendas along ICMJE authorship requirements, including and beyond criterion 1 .

\section{CRITERION 2}

Drafting the work or revising it critically for important intellectual content.

The second criterion is easily used to exclude, where an invitation is not extended to deserving LMIC team members to contribute. Reasons for non-invitation from team leadership may include perceived lack of writing or intellectual capacity ${ }^{12}$ or lack of interest among LMIC team members, who may also undervalue scientific authorship or value it differently from HIC members. ${ }^{17}$ This is another capacity-building opportunity, to build skills and thus justify inclusion. To ensure that those who meet criterion 1 have ample opportunity to meet criterion 2 , avenues by which the latter may be fulfilled can be expanded. To include typically excluded LMIC authors, these avenues may involve convening 'author contribution focus groups', using semistructured questionnaireguided group discussions which may be recorded and then transcribed. These contributions may be abstracted by more experienced authors in the evolving manuscript. More preferably, less experienced authors may be mentored to lead the writing phase.

'Author contribution focus groups' and similar strategies may work particularly well for the discussion section of a manuscript, which involves contextual interpretation of results. Alternatively, one-on-one calls may be held between less experienced and more experienced writers to capture the former's input and discuss framing of the narratives and arguments in the manuscript. These approaches stem from the notion that authorship contributions are not limited to 'putting pen to paper'; that writing itself is an interpretive process, that much of the framing of a manuscript occurs during writing, and that this interpretive process could be conducted virtually and/or verbally. Such approaches allow for expanded capture of authors' intellectual input, especially for those still learning scientific writing, or who may not be highly literate in the (typically European) language of the manuscript. The use of free online translation tools may facilitate contribution where language differences constitute a barrier. ${ }^{8}$

There is an additional issue of the interest and willingness of LMIC partners to be involved in writing or included as authors. In some cases, this is due to less emphasis on scientific authorship for career progression (especially in non-research health fields), or because they are so involved in non-research career activities that they have little time and resources to invest in academic writing and publishing. In such cases, it should be the responsibility of team leadership to persuade potential local authors that it may be in the best interest of such local team members to fulfil author criteria and be named as such. If they fulfil criterion 1, team leadership can provide opportunities and support for LMIC members to additionally fulfil criteria $2-4$ and become named contributing authors.

\section{CRITERION 3}

Final approval of the version to be published.

Facilitating inclusion via criteria 1 and 2 can be timeintensive. Research and authorship teams must be sufficiently patient to accommodate the time needed for experienced members to support and build the capacity of less experienced local team members to learn and to make meaningful contributions per the ICMJE criteria. This same consideration holds for criterion 3, which involves the required time and processes for final manuscript approval and sign-off for each author. Language differences may be an issue, in which case online translation tools or live translation may be used to facilitate equitable completion of this criterion. All team members may have limited availability, but local team members may be 
more likely to have limited time to dedicate further to research activities. As for criterion 2, fulfilling criterion 3 may require LMIC team members being given ample opportunity to sign off on the final manuscript version. The sign-off could be conducted verbally, ${ }^{8}$ by email or other forms of electronic communication-for example, via a video conference call with the final version shared on-screen.

\section{CRITERION 4}

Agreement to be accountable for all aspects of the work in ensuring that questions related to the accuracy or integrity of any part of the work are appropriately investigated and resolved.

A relatively recent addition to the ICMJE criteria, criterion 4 speaks to the willingness of authors to cooperate among themselves and with journal editors to investigate and resolve any potential allegations of misconduct related to the work. Hence, meeting criterion 4 is up to every individual who has already met criteria 1, 2 and 3. It reflects the extent to which all such individuals are confident in the integrity of their and fellow authors' work, that they are able to be publicly responsible for it, and to answer questions that may arise regarding issues of integrity about any aspect of the work, even when the questions are not about their own specific contribution. ${ }^{18}$ It means that each author is aware of who did what. ${ }^{19}$ Meeting criterion 4 is also a signal of ownership. If local LMIC authors do not feel they are able to fulfil criterion 4 , it indicates they do not sufficiently own the work, which in turn indicates they did not sufficiently own the process and the research that led to the publication.

\section{THE 'AND' CONDITION IN THE ICMJE CRITERIA}

It has been argued that the 'and' condition (that all authors must fulfil all four criteria) encourages or provides excuse for exclusion; ${ }^{8-10}$ for example, the exclusion of LMIC authors, who may easily fulfil criterion 1 , but who may not have the skills, the willingness and/or the opportunity to fulfil criteria $2-4 .{ }^{8}$ What the 'and' condition does, however, is signal that the intellectual function of authorship has both an interpretive dimension (ie, it is not enough to fulfil criterion 1 , it is also essential to participate in the interpretive element of the writing process in criteria 2 and 3 ) and an accountability dimension (ie, signing off on the final version and being willing and able to take responsibility for the work in criteria 3 and 4). The 'interpretation' element in criterion 1, which is made more comprehensive by layered input in criteria 2 and 3 , is an essential component of authorship that must be preserved. Contrary to being an excuse for exclusion, the 'and' condition imposes a requirement to be comprehensively inclusive.

Exclusion of local LMIC authors may then be considered rooted in an exclusionary interpretation (intended or unintended) of the ICMJE criteria. This casts reasonable doubt on the inclusiveness of the work from conception to publication, and suggests interpretive marginalisation of local LMIC authors-which then also casts doubt on the validity of the work. ${ }^{16}$ Beyond scientific content, rejections or 'revise and resubmit' decisions from journals should also be based on assessments for exclusionary authorship, particularly as pertains local authors in HIC-LMIC global health research collaborations. We encourage journals to take this seriously when considering which manuscripts to send out for peer review or to accept for publication. Publishing manuscripts that fail to demonstrate substantial local ownership and contribution should be a rare exception and no longer commonplace. Such studies smack of parachute research, may not meet local needs and are unlikely to be locally useful. ${ }^{20}$

\section{CONCLUSION}

The widely adopted ICMJE authorship criteria can be used inclusively to minimise parachute research. We welcome the 'Consensus statement on measures to promote equitable authorship of research publications from international partnerships'. ${ }^{11}$ In so doing, we call on biomedical and health journals to require, along with published manuscripts, the copublication of research team 'reflexivity' statements, structured to highlight considerations (or lack thereof) for local LMIC team members' ownership of the research, and promote inclusive authorship. However, we recognise that concerns of exclusion are also applicable to internal collaborations within HICs or LMICs. Like international-local exclusions, partnerships within countries also perpetuate authorship exclusion of local actorsfor example, data collectors, junior researchers, nonacademics and members of marginalised social groups (based on gender, class, caste, income, race, etc). Authorship exclusion within countries (HIC or LMIC) deserves similar attention and should be an important next step for consideration among biomedical and health journals.

Twitter Nadia Adjoa Sam-Agudu @NASAdoc and Seye Abimbola @seyeabimbola

Funding SA is currently supported by the National Health and Medical Research Council (NHMRC) of Australia through an Overseas Early Career Fellowship (APP1139631).

Competing interests SA is the Editor in Chief of BMJ Global Health

Patient consent for publication Not required.

Provenance and peer review Not commissioned; internally peer reviewed.

Data availability statement There are no data in this work.

Open access This is an open access article distributed in accordance with the Creative Commons Attribution Non Commercial (CC BY-NC 4.0) license, which permits others to distribute, remix, adapt, build upon this work non-commercially, and license their derivative works on different terms, provided the original work is properly cited, appropriate credit is given, any changes made indicated, and the use is non-commercial. See: http://creativecommons.org/licenses/by-nc/4.0/.

\section{ORCID iDs}

Nadia Adjoa Sam-Agudu http://orcid.org/0000-0001-5052-7730

Seye Abimbola http://orcid.org/0000-0003-1294-3850 


\section{REFERENCES}

1 International Committee of Medical Journal Editors. Guidelines on authorship. Br Med J 1985;291:722.

2 Hoey J. Who wrote this paper anyway?The new Vancouver Group statement refines the definition of authorship. CMAJ 2000;163:716-7.

3 Stephenson J. ICMJE: All authors of medical journal articles have "responsibility to stand by the integrity of the entire work". JAMA 2013;310:1216.

4 International Committee of Medical Journal Editors. Recommendations for the conduct, reporting, editing, and publication of scholarly work in medical journals [Internet]. Available: http://www.icmje.org/recommendations

5 Nylenna M, Fagerbakk F, Kierulf P. Authorship: attitudes and practice among Norwegian researchers. BMC Med Ethics 2014;15:53.

6 Patience GS, Galli F, Patience PA, et al. Intellectual contributions meriting authorship: survey results from the top cited authors across all science categories. PLoS One 2019;14:e0198117.

7 Abbasi K. End the farce; a new approach to authorship. J $R$ Soc Med 2012;105:361.

8 Smith E, Hunt M, Master Z. Authorship ethics in global health research partnerships between researchers from low or middle income countries and high income countries. BMC Med Ethics 2014;15:42.

9 Matheson A. How industry uses the ICMJE guidelines to manipulate authorship--and how they should be revised. PLoS Med 2011;8:e1001072.
10 Moffatt B. Orphan papers and ghostwriting: the case against the ICMJE criterion of authorship. Account Res 2013;20:59-71.

11 Morton B, Vercueil A, Masekela R, et al. Consensus statement on measures to promote equitable authorship of research publications from international partnerships. Anaesthesia 2021. doi:10.1111/ anae. 15597

12 Faure MC, Munung NS, Ntusi NAB, et al. Mapping experiences and perspectives of equity in international health collaborations: a scoping review. Int J Equity Health 2021;20:28

13 Erondu NA, Aniebo I, Kyobutungi C, et al. Open letter to international funders of science and development in Africa. Nat Med 2021;27:742-4.

14 Stocks A, Simcoe D, Toroser D, et al. Substantial contribution and accountability: best authorship practices for medical writers in biomedical publications. Curr Med Res Opin 2018;34:1163-8.

15 The World Bank. Data on Statistical Capacity [Internet], 2020. Available: https://datatopics.worldbank.org/statisticalcapacity/

16 Bhakuni $\mathrm{H}$, Abimbola S. Epistemic injustice in academic global health. Lancet Glob Health 2021;9:e1465-70.

17 Rees CA, Keating EM, Dearden KA, et al. Importance of authorship and inappropriate authorship assignment in paediatric research in low- and middle-income countries. Trop Med Int Health 2019:24:1229-42.

18 Alfonso F. Authorship: from credit to accountability. Neth Heart J 2019;27:289-96.

19 Ali MJ. ICMJE criteria for authorship: why the criticisms are not justified? Graefes Arch Clin Exp Ophthalmol 2021;259:289-90.

20 Abimbola S. The uses of knowledge in global health. BMJ Glob Health 2021:6:e005802. 